\title{
The Use of Pinus radiata Sawdust or Bark, or Zeolite to Reduce E. coli in Stand-Off Pads or Associated Drainage
}

\author{
A.M. Donnison ${ }^{*}$ and C.M. Ross
}

AgResearch, Ruakura Campus, Private Bag 3213 Hamilton, New Zealand

\begin{abstract}
Cow dung slurry containing a total of $7.4 \times 10^{5}$ E. coli was applied to laboratory-scale microcosms of Pinus radiata sawdust or bark. Rainfall was simulated by application of water at rates of $25 \mathrm{~mm} \mathrm{~h}^{-1}$ or $50 \mathrm{~mm} \mathrm{~h}^{-1}$ over $30 \mathrm{~min}$ utes. For sawdust $5 \%$ and $11 \%$ (respectively) of the $E$. coli were transferred to drainage compared to $12 \%$ and $28 \%$ for bark. After collection of drainage less than $10 \%$ of the retained $E$. coli were recovered from sawdust compared to about $90 \%$ for bark. Stand-off pad drainage $\left(10^{2}\right.$ E. coli $\left.100 \mathrm{~mL}^{-1}\right)$ was passed through laboratory-scale microcosms at $0.42 \mathrm{~mL}$ $\min ^{-1}$ for 4 weeks. The $E$. coli concentration was reduced by $1.5 \log _{10}$ for sawdust microcosms but there was no significant reduction for bark and zeolite. $P$. radiata sawdust seems an unfavourable environment for $E$. coli and its use in stand-off pads could reduce transmission of faecal microbes from dairy farms to waterways.
\end{abstract}

Keywords: Pinus radiata, sawdust, bark, Escherichia coli, manure, stand-off pads, stand-off pad drainage, dairy farms.

\section{INTRODUCTION}

In a report on environmental issues associated with New Zealand farming [1] the Parliamentary Commissioner noted that many waterways have faecal microbial loadings that are unsuitable for recreation or as source water for drinking. As well, concentrations can increase substantially after heavy or prolonged rainfall due to flow-generated inputs and resuspension of sediments $[2,3]$. Infectious faecal microorganisms are present in a wide range of warm-blooded animals. When shed by livestock there is potential for these microorganisms to enter waterways by direct deposition or indirectly as contaminants in surface and sub-surface flows following rainfall or irrigation [4]. Concentrations in surface flows are particularly high when animals graze on wet pasture [5-7]. Escherichia coli is a consistent constituent of the faeces of all warm blooded animals so that its presence in water "indicates" faecal contamination [8]. Extensive studies of New Zealand recreational freshwaters identified a relationship between $E$. coli concentrations and health risk [9]. New Zealand authorities have produced microbiological guidelines for freshwater that are based on E. coli [10].

An increasingly popular winter management strategy on dairy farms is to remove cows from wet pastures to animal houses (herd homes) or stand-off pads. One of the outcomes of such removal is a reduced likelihood of transferring contaminants to natural water bodies [11]. Stand-off pads are typically unroofed structures on which dairy cows are held for various lengths of time. An essential component of a stand-off pad is a drainage collection system that retains liquid seepage and prevents contaminants being transferred to surrounding land. Pads can be constructed from free-draining materials including sawdust, bark, woodchips, lime or soft rock. The type of pad materials may influence capture and retention of contaminants as it has been reported that faecal microbial capture and survival are related to the type of

*Address correspondence to this author at the AgResearch, Ruakura Campus, Private Bag 3213 Hamilton, New Zealand;

E-mail: andrea.donnison@agrsearch.co.nz bedding material used in animal-houses. For example, Miller et al. [12] reported lower concentrations of coliform bacteria in runoff when straw was used as feedlot bedding material compared to wood chips made from pine and spruce. Zehner et al. [13] noted that in contrast to softwood sawdust that had a bactericidal effect, there was rapid growth of three bacterial species associated with mastitis when straw and some hardwood chips were used.

The relationship between bacterial die-off and bedding material may not be straightforward. Davis et al. [14] reported that the pathogen Escherichia coli $\mathrm{O} 157: \mathrm{H} 7$ grew in cedar chip bedding moistened with urine in contrast to a decline when the bedding was moistened with water. LeJeune and Kauffman [15] measured differences in survival of $E$. coli $\mathrm{O} 157: \mathrm{H} 7$ in sawdust and sand and also prevalence rates in animals using these materials as bedding. These workers reported both higher survival and higher prevalence rates for sawdust than for sand, but the type of wood was not stated. A comparison of the bactericidal properties of wood was carried out by Milling et al. [16] who measured the survival of two faecal bacteria, E. coli and Enterococcus faecium, in the sawdust made from seven wood types. These workers found survival rates were related to microbial species and wood type, and were also affected by environmental factors including ambient temperature and humidity. Under typical ambient conditions (temperature $21^{\circ} \mathrm{C}$ and relative humidity $55 \%$ ) and for both test bacteria, the most rapid decline was observed on pine sawdust, followed by oak.

Luo et al. [17] investigated the environmental performance of unroofed stand-off pads constructed from either fine crushed bark or sawdust (both prepared from untreated Pinus radiata) overlaid with coarse bark. These workers calculated removal efficiency as faecal microbial inputs could only be estimated. They reported that drainage from the bark pad contained consistently higher concentrations of E. coli than that from the sawdust pad, with a similar trend observed for the pathogen Campylobacter jejuni.

This paper reports a laboratory-based study that was carried out to quantify the retention of E. coli by sawdust and 
bark under different levels of rainfall. As well, three natural materials, sawdust, bark and zeolite were tested as possible treatment options to reduce $E$. coli concentrations in standoff pad drainage to levels that would be acceptable for disposal to the environment.

\section{MATERIALS AND METHODS}

The sawdust and bark used in this study were prepared from untreated Pinus radiata. These materials were obtained from a commercial supplier (Daltons Ltd, Matamata NZ). The bark had been stored outdoors and the sawdust was freshly milled. To maintain their natural state these materials were not subjected to any disinfection treatment (e.g. heat) prior to use.

\section{Interactions of $E$. coli with Sawdust and Bark}

Sawdust and bark (particle size 3-10 mm) were soaked for about $6 \mathrm{~h}$ in excess water and drained overnight. Microcosms were prepared by adding the prepared material to plastic sleeves (220 mm diam., $100 \mathrm{~mm}$ high). Five microcosms of each material were prepared (sawdust microcosms contained about $1600 \mathrm{~g}$ and bark about $2130 \mathrm{~g}$ (wet weight)).

To ensure even application across the surface of all microcosms, slurry was prepared by thoroughly mixing $10 \mathrm{~g}$ fresh cow dung (faeces) with $1 \mathrm{~L}$ of water. Over a 45 minute period $100 \mathrm{~mL}$ of slurry was applied evenly (using a Pasteur pipette) over the surface of each microcosm. Three microcosms were treated in the same way for each material. A further microcosm (control) of each material received 100 $\mathrm{mL}$ of distilled water applied in the same way.

Each microcosm was placed on a shallow perforated tray containing gravel that was then placed on a drainage collection bucket. After application of slurry, or water, the microcosms were placed in a controlled temperature room at $4{ }^{\circ} \mathrm{C}$ and left overnight. During this period no drainage was collected, demonstrating that all of the applied slurry remained within the microcosm.

A plastic squeeze bottle fitted with a dropper was filled with water and used to apply simulated rainfall. Two slurrycontaminated microcosms of each material (i.e. sawdust and bark) received simulated rainfall at two rates. To achieve a rate of $25 \mathrm{~mm} \mathrm{~h}^{-1} 475 \mathrm{~mL}$ of water was applied evenly over the entire surface of a microcosm over 30 minutes. For 50 $\mathrm{mm} \mathrm{h}^{-1} 950 \mathrm{~mL}$ was applied over 30 minutes. The "control" microcosms received simulated rainfall at $25 \mathrm{~mm} \mathrm{~h}^{-1}$ in the same way.

Drainage from each microcosm was collected over about an hour after rainfall application (or until no more drainage was collected). The drainage volume was measured and a sub-sample analysed for $E$. coli. The microcosms were returned to the $4^{\circ} \mathrm{C}$ room and left overnight. The following day a second application of simulated rainfall was applied as described above. Following the drainage collection, the contents of each microcosm were separately and thoroughly mixed and a portion (about $500 \mathrm{~g}$ ) retained for E. coli analysis.

\section{Survival of $E$. coli RR in Sawdust}

To determine whether the poor recovery of E. coli from sawdust was an artefact of analysis due to "overgrowth" by closely related bacterial species in the microbiological growth medium, a laboratory grown strain, E. coli HS (pFamp)R [18]- designated RR, that is resistant to the antibiotics ampicillin and streptomycin, was added to sawdust.

E. coli RR was grown in tryptic soy broth (TSA, Difco, USA) plus antibiotics [18] for $24 \mathrm{~h}$ at $35^{\circ} \mathrm{C}$ and serially diluted in $0.1 \%$ yeast extract (YE) to obtain target concentrations of $10^{8}, 10^{6}$ and $10^{4}$ E. coli $100 \mathrm{~mL}^{-1}$ (designated high, medium and low respectively). $10 \mathrm{~mL}$ portions of each dilution were placed in a Universal bottle as "minus sawdust" controls. A $300 \mathrm{~mL}$ portion of each dilution was added to $250 \mathrm{~g}$ sawdust and thoroughly mixed. This proportion of liquid to sawdust allowed thorough wetting without separation into a liquid and solid phase.

All treatments were incubated at $15^{\circ} \mathrm{C}$ for 28 days after which they were analysed for E. coli.

\section{Using Natural Materials to Reduce $E$. coli in Drainage from Stand-Off Pads}

About $50 \mathrm{~L}$ of liquid was collected from the drainagecollection sump at a sawdust stand-off pad located on a dairy farm and stored at $4^{\circ} \mathrm{C}$ over a 4 week study period.

Small microcosms, (plastic sleeves - capacity 1 L), 4 for each material were prepared using sawdust, bark (particle size $3-10 \mathrm{~mm}$ ) or crushed zeolite (similar particle size to bark). Prior to filling, the materials were soaked in excess water, the sleeves filled and drained under gravity overnight. Stand-off pad drainage liquid (influent) was dripped continuously through each microcosm at a rate of $0.42 \mathrm{~mL} \mathrm{~min}^{-1}$ (i.e. each column received $0.6 \mathrm{~L} \mathrm{~d}^{-1}$ ) for about 4 weeks (microcosm contents were not replaced during this time). On 10 occasions, at approximately equal intervals and commencing $24 \mathrm{~h}$ after the experiment began, samples of effluent were collected from each microcosm. At the same time a subsample was also taken from the influent holding vessel. Two such experiments were carried out.

\section{E. coli Analysis}

Liquid samples, and solid samples that contained high concentrations of $E$. coli were analysed by a defined substrate method [19; Method 9223B] using the Colilert/ Quantitray $2000^{\mathrm{TM}}$ technique (IDEXX, Westbrook ME, USA). The limit of detection was 1 E. coli $100 \mathrm{ml}^{-1}$ in drainage and 100 E. coli $100 \mathrm{~g}^{-1}$ in solid material.

For solid samples, in which E. coli numbers were too low for detection by the method described above, a traditional Most Probable Number (MPN) method was used [19; Methods $9221 \mathrm{~B}$ and 9221F-1]. For this MPN method the 3consecutive dilution series was inoculated by direct addition of $5 \times: 10 \mathrm{~g}, 1 \mathrm{~g}$ and $0.1 \mathrm{~g}$ portions, to the microbiological growth medium (so as to include those $E$. coli that were attached to the solid material in the count). The limit of detection was 2 E. coli $100 \mathrm{~g}^{-1}$ of solid material.

To confirm E. coli identification selected isolates (both positive and negative) were identified using Enterobacteriaceae test kits (Microbact Ltd., Australia), used in accordance with the manufacturer's directions.

Data were $\log _{10}$ transformed and ANOVA (Minitab Inc., USA) performed for statistical analysis. 


\section{RESULTS}

\section{Retention of $\boldsymbol{E}$. coli by Sawdust or Bark}

The total number of $E$. coli in the cow dung slurry applied to each microcosm was $7.4 \times 10^{5}$. A substantial fraction of the water applied as simulated rainfall was collected as drainage, demonstrating that the microcosms were freedraining. At the lower $\left(25 \mathrm{~mm} \mathrm{~h}^{-1}\right)$ application rate drainage recovery was $92 \%$ and $85 \%$ of the volume applied for sawdust and bark, respectively, and at the higher $\left(50 \mathrm{~mm} \mathrm{~h}^{-1}\right)$ rate, the recoveries were $95 \%$ and $93 \%$, respectively.

The number of $E$. coli transferred to drainage from the slurry-contaminated microcosms at each rainfall rate, and the number remaining in the material (both results also expressed as a percentage of the number of $E$. coli applied) are shown in Table 1 . No $E$. coli were recovered from uncontaminated sawdust or drainage but "natural" $E$. coli were identified in bark microcosm drainage $\left(2.4 \times 10^{3} \mathrm{E}\right.$. coli after the first rainfall application and $1.2 \times 10^{3} \mathrm{E}$. coli after the second) therefore results for contaminated bark microcosms were corrected for "background".

The data in Table 1 demonstrate more of the applied $E$. coli were transported to drainage at the higher $\left(50 \mathrm{~mm} \mathrm{~h}^{-1}\right)$ rate. As well, the percentage of applied E. coli leached from sawdust was less than that from bark at both rates of rainfall. As shown in Table 1, for bark microcosms the majority of the applied $E$. coli could be accounted for in either the drainage or the bark itself $\left(90 \%\right.$ at $25 \mathrm{~mm} \mathrm{~h}^{-1}$ and $97 \%$ at $50 \mathrm{~mm}$ $\mathrm{h}^{-1}$ ). In contrast, for sawdust microcosms the number of the applied $E$. coli that could be accounted for was only $11 \%$ at $25 \mathrm{~mm} \mathrm{~h}^{-1}$ and $16 \%$ at $50 \mathrm{~mm} \mathrm{~h}^{-1}$.

\section{Determination of $E$. coli RR Survival in Sawdust}

When $E$. coli RR was incubated at $15^{\circ} \mathrm{C}$ in yeast extract in the absence of sawdust, irrespective of the initial number of $E$. coli (i.e. high, medium or low) after two days numbers had increased to $10^{9}$ or $10^{10}$ E. coli $100 \mathrm{~mL}^{-1}$ and did not decline over the 28 day period. In contrast, when E. coli RR mixed with sawdust was incubated under the same conditions numbers declined substantially after 28 days, for all three inoculum levels, as shown in Table 2, by at least $99.9 \%$ (i.e. $3 \operatorname{logs}$ ) of the original inoculum number.

\section{Removal of $E$. coli from Stand-Off Pad Drainage}

The concentration of $E$. coli in the drainage used as microcosm influent in the first experiment did not vary much (geometric mean $1.9 \times 10^{2}$ E. coli $100 \mathrm{~mL}^{1}$, sd $1.7 \log _{10}$ ) over the course of the experiment. As shown in Fig. (1), the $E$. coli concentration in the effluent that was collected from the sawdust microcosms decreased by about $1.5 \log _{10}$ over the course of the 4 week experiment and this reduction was statistically significant $(P<0.05)$. There was little difference in $E$. coli concentration in the influent and in the effluent from the zeolite microcosm $(P>0.05)$ but concentrations were consistently lower in bark effluent. However, the reduction in $E$. coli due to passage through bark was not statistically significant $(P>0.05)$.

In the second experiment the bark was found to have a substantial population of natural $E$. coli that resulted in bark microcosm effluent $E$. coli concentration (overall average 9.8 $\times 10^{2}$ E. coli $100 \mathrm{~mL}^{-1}$, sd 3.3) being five times higher than that of the applied influent. As a consequence, the results for the bark microcosms were not evaluated further. The E. coli concentration in the influent remained reasonably constant over the course of this experiment (geometric mean $2 \times 10^{2}$ E. coli $100 \mathrm{~mL}^{-1}$, sd $1.3 \log _{10}$ ). As shown in Fig. (2), there was again a substantial decline in $E$. coli after passage through the sawdust microcosms $(P<0.05)$. As for the first experiment, there was little difference between the $E$. coli numbers in the influent and those in the effluent from the zeolite microcosms $(P>0.05)$.

Although there was a significant reduction in E. coli after passage through sawdust in both experiments, removal rates differed (as determined by simple linear regression) being $0.196 \log _{10} E$. coli $\mathrm{d}^{-1}$ in the first experiment and $0.057 \log _{10}$ E. coli $\mathrm{d}^{-1}$ in the second.

\section{DISCUSSION}

The application of simulated rainfall transferred some of the Escherichia coli from the cow dung slurry layered on top of the sawdust and bark to the microcosm drainage. The percentage transferred to sawdust drainage, under both the low and high rainfall rates, was only about half of that for bark ( $5 \%$ and $11 \%$ compared to $12 \%$ and $28 \%$, respectively). However, the most notable difference between these two materials was an apparent "loss" of E. coli in the sawdust as

Table 1. E. coli Recovered in Drainage or Microcosm Material after Application of Simulated Rainfall at Two Rates to Sawdust and Bark Microcosms Contaminated with Cow Dung Slurry

\begin{tabular}{|c|c|c|c|c|c|c|c|c|}
\hline & \multicolumn{4}{|c|}{ E. coli $\left(100 \mathrm{~mL}^{-1}\right.$ or $\left.100 \mathrm{~g}^{-1}\right)$} & \multicolumn{4}{|c|}{ E. coli $\left(100 \mathrm{~mL}^{-1}\right.$ or $\left.100 \mathrm{~g}^{-1}\right)$} \\
\hline & $\mathbf{A}$ & B & Mean & $\%$ of Applied E. coli & $\mathbf{A}$ & B & Mean & $\%$ of Applied E. coli \\
\hline Sawdust & \multicolumn{4}{|c|}{$25 \mathrm{~mm} \mathrm{~h}^{-1}$} & \multicolumn{4}{|c|}{$50 \mathrm{~mm} \mathrm{~h}^{-1}$} \\
\hline Drainage & $5.0 \times 10^{4}$ & $2.4 \times 10^{4}$ & $3.4 \times 10^{4}$ & 5 & $8.7 \times 10^{4}$ & $7.9 \times 10^{4}$ & $8.3 \times 10^{4}$ & 11 \\
\hline Remaining in sawdust & $8.0 \times 10^{4}$ & $2.7 \times 10^{4}$ & $4.6 \times 10^{4}$ & 6 & $3.7 \times 10^{4}$ & $3.4 \times 10^{4}$ & $3.5 \times 10^{4}$ & 5 \\
\hline Bark & \multicolumn{4}{|c|}{$25 \mathrm{~mm} \mathrm{~h}^{-1}$} & \multicolumn{4}{|c|}{$50 \mathrm{~mm} \mathrm{~h}^{-1}$} \\
\hline Drainage & $8.9 \times 10^{4}$ & $7.3 \times 10^{4}$ & $8.8 \times 10^{4}$ & 12 & $2.5 \times 10^{5}$ & $1.7 \times 10^{5}$ & $2.0 \times 10^{5}$ & 28 \\
\hline Remaining in bark & $5.8 \times 10^{5}$ & $5.8 \times 10^{5}$ & $5.8 \times 10^{5}$ & 78 & $1.0 \times 10^{6}$ & $2.5 \times 10^{5}$ & $5.0 \times 10^{5}$ & 69 \\
\hline
\end{tabular}

Data are the results obtained for each of the duplicate microcosms (i.e. A and B) for each treatment and the geometric mean. The recovery of $E$. coli in drainage or remaining afte rain was calculated as a percentage of the number of $E$. coli applied. 
more than $80 \%$ of the applied $E$. coli were not recovered from either the drainage or the sawdust itself. In contrast more than $90 \%$ of the applied $E$. coli were recovered from the bark plus its drainage. The observed high recovery from bark microcosms and the relatively short experimental timeframe suggests that the sawdust result was not due to "natural die-off" during the experiment.

Table 2. E. coli RR $\left(\log _{10} E\right.$. coli $\left.100 \mathrm{~g}^{-1}\right)$ Recovery from Sawdust at Three Levels of Contamination, Designated Low, Medium and High, after 28 Days Storage at $15^{\circ} \mathrm{C}$

\begin{tabular}{|c|c|c|c|}
\hline & \multicolumn{3}{|c|}{$E$. coli $\left(\log _{10} \mathbf{1 0 0}^{-1}\right.$ Sawdust) } \\
\hline \hline Time & Low & Medium & High \\
\hline Day of inoculation & 4.36 & 6.54 & 8.59 \\
\hline After 28 days & 1.36 & 3.34 & 4.54 \\
\hline
\end{tabular}

A higher rate of bacterial adsorption would be expected in sawdust due to a larger surface area compared to bark but it is unlikely that this explained the low recovery of $E$. coli as the MPN test was done by direct addition of weighed portions of sawdust to microbiological enrichment broth. This procedure was adopted to allow any viable $E$. coli that were firmly attached to sawdust particles to grow during incubation. As the analysis of $E$. coli was by laboratory culture it is not known whether the unaccounted for $E$. coli cells had entered a non-culturable state [20] or were dead. In either event, it seems that Pinus radiata sawdust is an unfavourable environment for $E$. coli but that this does not apply to $P$. radiata bark.

There are conflicting reports on the antibacterial nature of wood products. For example Zehner et al. [13] found there was a rapid decline in three bacterial species associated with mastitis when paper and softwood sawdust were used as bedding materials but LeJeune and Kauffmann [15] reported a higher prevalence of $E$. coli $\mathrm{O} 157: \mathrm{H} 7$ in sawdust than in sand bedding. Milling et al. [16] reported that pine sawdust had substantially better hygienic performance than five other wood species and also plastic.

Escherichia coli RR grew rapidly in yeast extract at $15^{\circ} \mathrm{C}$ and survived over the 4 week experimental period. However, in a parallel experiment carried out in the presence of sawdust, there was a substantial decrease, of at least $3 \operatorname{logs}$, in $E$. coli RR numbers. This observed decline in sawdust was about 10-fold greater than that reported for soils [21, 22]. Analysis for E. coli (by both methods used in this study) is a two-stage process. In the first stage coliforms are recovered and in the second those coliforms that are E. coli are identified [19]. Large numbers of coliforms, most of which were found to be Klebsiella oxytoca, were identified in the samples of sawdust that were analysed for E. coli. Klebsiella species can fix nitrogen, grow well on carbohydrates and have a known association with timber processing waste streams [23]. K. oxytoca and E. coli are members of the same family (Enterobacteriaceae) and share a number of properties, so it is possible that $K$. oxytoca could have "masked" the presence of $E$. coli. If this were the case then the apparent loss of $E$. coli in sawdust would be an artefact of the analytical procedure. The use of an antibiotic resistant strain $(E$. coli RR) that could be measured without interference from closely related but antibiotic sensitive bacteria such as Klebsiella spp. confirmed that sawdust is not a favourable environment for $E$. coli and that the observed decline in numbers was in fact real.

Two of the three batches of $P$. radiata bark used over the course of this study were found to contain natural E. coli, presumably due to contamination with animal (e.g. bird) faeces during outdoor storage. Unlike sawdust we did not observe a significant decline in $E$. coli numbers in bark microcosms. No natural $E$. col $i$ were found in the freshly milled sawdust and there was a significant reduction in E. coli in all experimental sawdust microcosms.

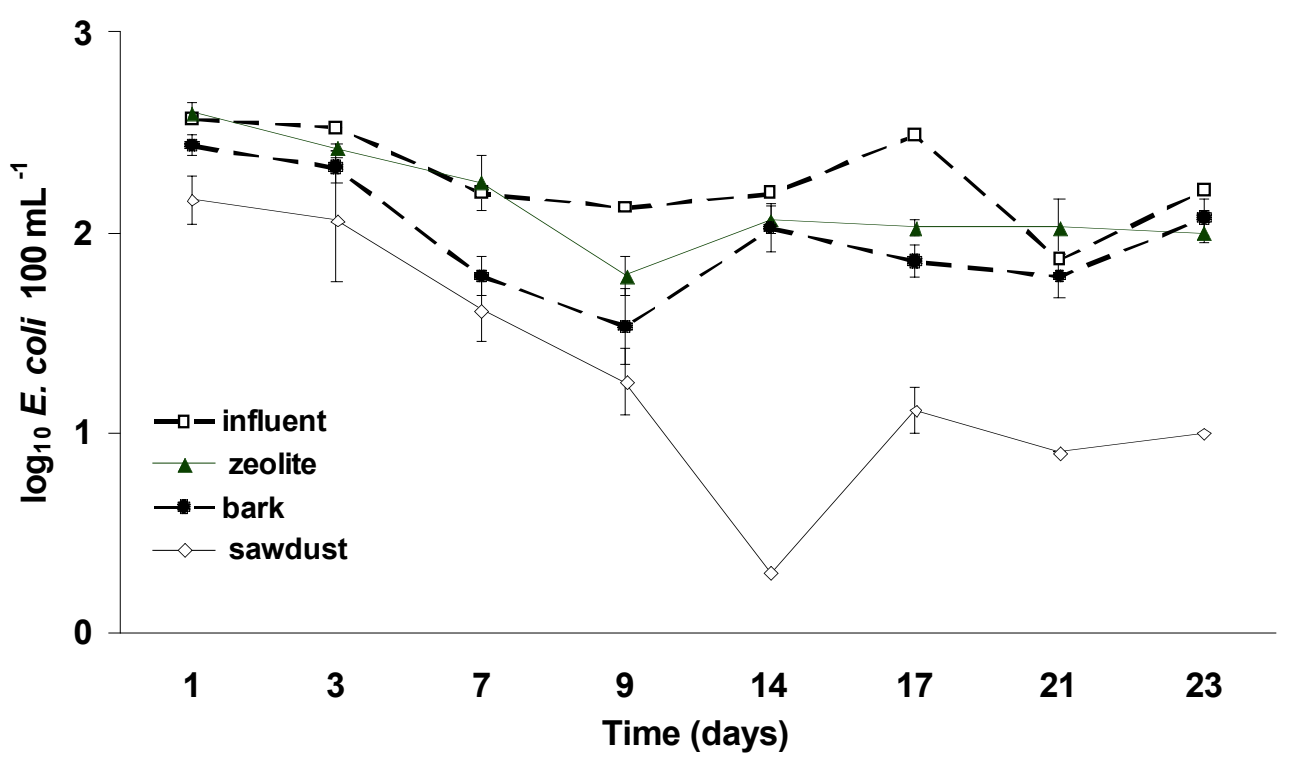

Fig. (1). Numbers of E. coli $100 \mathrm{~mL}^{-1}$ recovered in influent (stand-off pad drainage) applied to microcosms of sawdust, bark or zeolite and in the effluent from these microcosms. For each material data are the average (and SEM) for 4 microcosms and for the influent represent the number of E. coli measured on the day of analysis. 


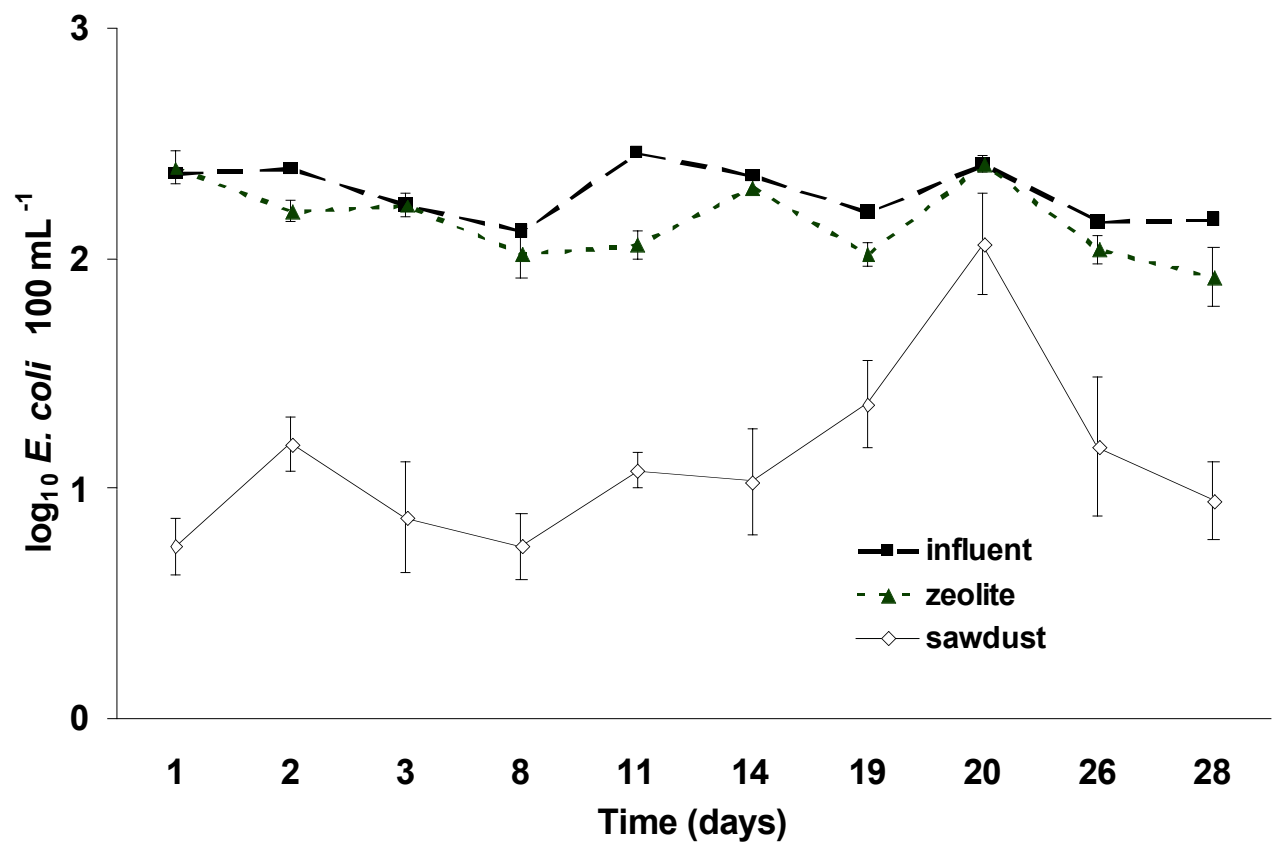

Fig. (2). Numbers of E. coli $100 \mathrm{~mL}^{-1}$ recovered from influent (stand-off pad drainage) applied to microcosms of sawdust or zeolite and in the effluent from these microcosms. For the two materials data are the average (and SEM) for 4 microcosms and for the influent represent the number of $E$. coli measured on the day of analysis.

There were differences in removal rates of $E$. coli from stand-off pad drainage in two microcosm studies indicating that further work is needed to optimise this procedure. At a full-scale stand-off pad on a dairy farm, a lower recovery of both E. coli and the pathogen Campylobacter was observed in sawdust than in bark drainage [17] suggesting that sawdust may be inhibitory to other bacteria as well as E. coli. Further work is needed to determine the fate of $E$. coli, the mechanism of it's inhibition by $P$. radiata sawdust and the range of bacteria that are inhibited.

\section{CONCLUSIONS}

When $E$. coli was washed through $P$. radiata sawdust, there was a substantial reduction in numbers suggesting that the use of this sawdust in stand-off pads would be a useful way of reducing transfer of faecal microorganism from dairy farms to the wider environment.

\section{ACKNOWLEDGEMENTS}

Stuart Lindsey (AgResearch) is thanked for technical assistance. Dr J. Luo and Dr K. Mueller are thanked for critical review of the manuscript. The project was funded by the New Zealand Foundation for Research Science and Technology under Contract C10X0320.

\section{REFERENCES}

[1] PCE 2004. Growing for good: intensive farming, sustainability and New Zealand's environment. October 2004; Wellington, NZ: Parliamentary Commissioner for the Environment. [Accessed 4 Nov 2007]. www.pce.govt.nz/reports/allreports/1 $877274 \quad 45 \quad 3 . s h t m l$

[2] Nagles JW, Davies-Colley RJ, Donnison AM, Muirhead RW. Faecal contamination over flood events in a New Zealand stream. Water Sci Technol 2002; 45: 45-52.

[3] Muirhead RW, Davies-Colley RJ, Donnison AM, Nagels JW. Faecal bacterial yields in artificial floods events: quantifying in-stream stores. Water Res 2004; 38: 1215-1224.
[4] Collins R, McLeod M, Hedley M, et al. Best management practices to mitigate faecal contamination by livestock of New Zealand waters. NZ J Agric Res 2007; 50: 267-278.

[5] Collins R, Donnison A, Ross C, McLeod M. Attenuation of effluent-derived faecal microbes in grass buffer strips. NZ J Agric Res 2004; 47: 565-574.

[6] Muirhead RW, Collins RP, Bremer PJ. Erosion and subsequent transport state of Escherichia coli from cowpats. Appl Environ Microbiol 2005; 71: 2875-2879.

[7] Gruber AK, Shelton DR, Pachepsky YA, Sadeghi AM, Sikora LJ. Rainfall-induced release of faecal coliforms and other manure constituents: comparison and modelling. Appl Environ Microbiol 2006; 72: 7531-7539.

[8] Ashbolt NJ, Grabow WOK, Snozzi M. Indicators of microbial water quality. In: Fewtrell L, Bartram J (Eds), Water Quality, Guidelines, Standards and Health. World Health Organisation, London 2001; pp. 289-316.

[9] McBride G, Till D, Ryan T, et al. Freshwater Microbiology Research Programme: Pathogen Occurrence and Human Health Risk Assessment Analysis. Jointly published by the NZ Ministry of Health and the NZ Ministry for the Environment, Wellington. 2002; pp. 94.

[10] Ministry for the Environment publication 474 Microbiological Water Quality Guidelines for Marine and Freshwater Recreational areas. Ministry for the Environment, Wellington, 2003. [Accessed 23 January 2008]. www.mfe.govt.nz/publications/water/microbiological-quality-jun03/

[11] McDowell RW, Drewry JJ, Muirhead RW, Paton RJ. Restricting the grazing time of cattle to decrease phosphorus, sediment and $E$ coli losses in overland flow from cropland. Aust J Soil Res 2005; 43: 61-66.

[12] Miller JJ, Olson ECS, Chanasyk DS, et al. Bedding and within-pen location effects on feedlot pen runoff quality using a rainfall simulator. J Environ Qual 2006; 35: 505-515.

[13] Zehner MM, Farnsworth RJ, Appleman RD, Larntz K, Springer JA Growth of environmental mastitis pathogens in various bedding materials. J Dairy Sci 1986; 69: 1932-1941.

[14] Davis MA, Cloud-Hansen KA, Carpenter J, Hovde CJ. Escherichia coli O157:H7 in environments of culture positive cattle. Appl Environ Microbiol 2005; 71: 6816-6822.

[15] LeJeune JT, Kauffman MD. Effect of sand and sawdust bedding materials on the fecal prevalence of Escherichia coli O157:H7 in dairy cows. Appl Environ Microbiol 2005; 71: 326-330. 
[16] Milling A, Kehr R, Wulf A, Smalla K. Survival of bacteria on wood and plastic particles: Dependence on wood species and environmental conditions. Holzforschung 2005; 59: 72-81.

[17] Luo J, Donnison A, Ross C, Ledgard S, Longhurst B. Control of pollutants using stand-off pads containing different natural materials. Proceed N Z Grassland Assn 2006; 68: 315-320.

[18] Debartolomeis J, Cabelli V. Evaluation of an Escherichia coli host strain for enumeration of F Male-specific bacteriophages. Appl Environ Microbiol 1991; 57: 1301-1305.

[19] Eaton AD, Clesceri LS, Rice EW, Greenberg AE (Eds). Standard methods for the examination of water and wastewater. $21^{\text {st }}$ ed. Washington DC; American Public Health Assn; 2005.
[20] Byrd JJ. Morphological changes leading to the nonculturable state. In: Colwell RR, Grimes DJ (Eds). Nonculturable microorganisms in the environment. Washington, ASM Press, 2000; pp. 7-18.

[21] Sjogren RE. Prolonged survival of an environmental Escherichia coli in laboratory soil microcosms. Water Air Soil Poll 1994; 75: 389-403.

[22] Ross CM, Donnison AM. Campylobacter jejuni inactivation in New Zealand soils. J Appl Microbiol 2006; 101: 1188-1197.

[23] Clark T, Donnison A, Mitchell C. Bacteriological quality of pulp and paper mill effluents: the problem of Klebsiella pneumoniae. 11 p. 92 TAPPI Environmental Conference, Richmond Virginia, 1992 April 12-15. 